\title{
Contextual challenges and solutions to undertaking a household adolescent mental health survey in a developing country
}

Lilian A. Ghandour, ${ }^{1}$ Al Amira S. Shehab, ${ }^{2}$ Pia Zeinoun, ${ }^{3,4}$ Lucy Tavitian, ${ }^{4}$ Fadi Halabi ${ }^{3}$ and Fadi T. Maalouf ${ }^{3}$

${ }^{1}$ Department of Epidemiology and Population Health, Faculty of Health Sciences; ${ }^{3}$ Department of Psychiatry, Faculty of Medicine, American University of Beirut, Beirut, Lebanon (Correspondence to: Fadi Maalouf: fm38@aub.edu.lb).²Queens College, City University of New York, New York, United States of America. ${ }^{4}$ Department of Cross-cultural Psychology, Tilburg University, Tilburg, Netherlands.

\begin{abstract}
Recent epidemiological evidence for Lebanese adults along with the increased efforts for policy and service planning have demonstrated the importance of screening for rates of psychiatric disorders in the adolescent population. In response to this need, the Beirut Epidemiological Investigation of the Psychological Status of Youth was conducted in a community sample to estimate the prevalence of psychiatric disorders and their correlates among adolescents. The main aim of this report is to provide a synthesis of the research process and challenges faced in completing the first population-based mental health survey among children and adolescents in Lebanon. This report discusses the challenges faced and the lessons learnt in conducting such a survey. Themes discussed include working around the absence of a proper sampling framework, conducting a sound study with limited funding and the absence of a research culture. This report presents evidence-informed recommendations for similar future surveys. The report also establishes that a sound epidemiological survey is possible even where there are limited resources and challenging contexts such as security issues or the absence of a research culture.
\end{abstract}

Keywords: household survey, challenges, mental health, adolescents, Lebanon

Citation: Ghandour LA; Shehab AS; Zeinoun P; Tavitian L; Halabi F; Maalouf FT. Contextual challenges and solutions to undertaking a household adolescent mental health survey in a developing country. East Mediterr Health J. 2018;24(8):789-799. https://doi.org/10.26719/2018.24.8.789

Received: 20/06/16; accepted: 17/07/17

Copyright (C) World Health Organization (WHO) 2018. Some rights reserved. This work is available under the CC BY-NC-SA 3.o IGO license (https:// creativecommons.org/licenses/by-nc-sa/3.o/igo).

\section{Introduction}

There have been multiple attempts in Lebanon, mainly driven by nongovernmental organizations, to raise awareness and spread knowledge on the importance of the surveillance, prevention and management of mental illness among the Lebanese population. Recently, the Ministry of Health has partnered with the World Health Organization (WHO) to launch the Mental Health Gap Action Programme (mhGAP) aimed at scaling up mental health care services. Another critical milestone for Lebanon's mental health care sector has been the recent launch of the Mental Health and Substance Use Prevention, Promotion, and Treatment Strategy for Lebanon (2015-2020) (1), whose goals are in line with the WHO Global Action Plan for Mental Health.

Lebanon is a small country in the Middle East at the crossroad between oriental and western cultures. The country has experienced years of irregular bouts of political instability, security threats and civil wars, and this exposure to wars and war-related factors (e.g. displacement) has been linked to earlier onset of suicidal ideation and attempt (2), a greater likelihood of experiencing at least 1 mental health disorder (3) or specific disorders, including post-traumatic stress disorder, depression/anxiety and eating disorders (4-6). Despite the clear linkage between the deleterious effects of war on mental health in Lebanon and elsewhere $(2,5)$, a national mental health strategy was only recently launched.
The strategy covers 5 domains, including the use of evidence to inform mental health policy, practice and development, and improving access to care for vulnerable groups such as children and adolescents. Local available epidemiological data for children and adolescents have emanated mostly from targeted samples (e.g. children exposed to war), or have focused on specific disorders, clearly illustrating the necessity of better understanding the mental health profile and needs of youth in the general population. Previous research has shown that almost 1 in $6(16 \%)$ of middle school students in public and private schools reported suicide ideation in 2005 (7). Attention deficit hyperactivity disorder was also found in $3 \%$ of schoolchildren aged 6-10 years using teacher and parent rating scales (8). Moreover, and quite importantly, the onset of many mental health disorders among a representative sample of Lebanese adults aged $\geq 18$ years had occurred during adolescence or young adulthood (average 11 years for specific phobia, 14 years for social phobia, and 14 years for impulse control disorders) (9).

In an effort to gather population-based epidemiological evidence on youth that could feed into the development and evaluation of youth-friendly national policies and programmes, a household face-to-face survey was conducted in 2011-2012 among children and adolescents (aged 11 years to 17 years 11 months) residing in the capital city, Beirut (10). The study, the Beirut Epidemiological Investigation of the Psychiatric Status of Youth (BEI-PSY), examined the previous 30-day 
prevalence and correlates of several psychiatric disorders. Despite the challenges faced at various levels of the research process, some unique to Lebanon and others cross-cultural, BEI-PSY was successfully completed.

In general, sampling can been challenging in many contexts where official household listings, population registries or census information are unavailable; examples include studies from Ireland (11), the United Arab Emirates (12,13) and Bangladesh (14). Other challenges may be more specific to fieldwork, and can include fraud by interviewers (15), difficulty in recruiting or reaching cases (16), low response rate (17), lack of resources to carry out structured assessments (14) or to conduct community surveys drawn from a wide variety of urban and rural areas (15). Reporting issues may also prevail such as underreporting of religiously and morally taboo issues like alcohol or drug use in predominantly Muslim societies (14). Surveying a sensitive topic like mental health could also pose its own challenges. In Pakistan, for example, the low response rate was attributable to the stigma surrounding mental health, as well as general lack of awareness and concerns from parents on how results would be used (18). In a 2012 review of mental health research in the Arab world, a few potential factors contributing to the scarcity of mental health research endeavours in the region were identified; they included the lack of governmental support to conduct such research along with other more general factors such as lack of research infrastructure and limited research funding (19).

Specific challenges in conducting research in the Middle East region include low research support by both governmental and nongovernmental bodies, limited resources and difficulty in obtaining probability samples, not to mention instability and violence in some countries (20). In fact, conducting surveys in armed conflict areas, which includes countries that have experienced civil strife and wars such as Lebanon, may be challenged by lack of, or outdated, sampling frames impeding proper sample design and selection, or higher noncontact and/ or non-response rates during data collection (21).

This paper provides a synthesis of the research process and challenges faced as well as main lessons learnt after completing BEI-PSY, the first population-based mental health survey among children and adolescents in Lebanon. We feel that such a transparent and detailed documentation and synthesis detailing evidenceinformed potential ways of addressing such challenges is important for knowledge-sharing and guiding future research endeavours.

\section{Methodology: exposé and outcomes}

\section{Sampling and fieldwork}

Beirut was divided first into areas, and then into neighbourhoods (Table 1). The Central Administration of Statistics provided estimates of the number of households available by area (22); these were proportionately sampled

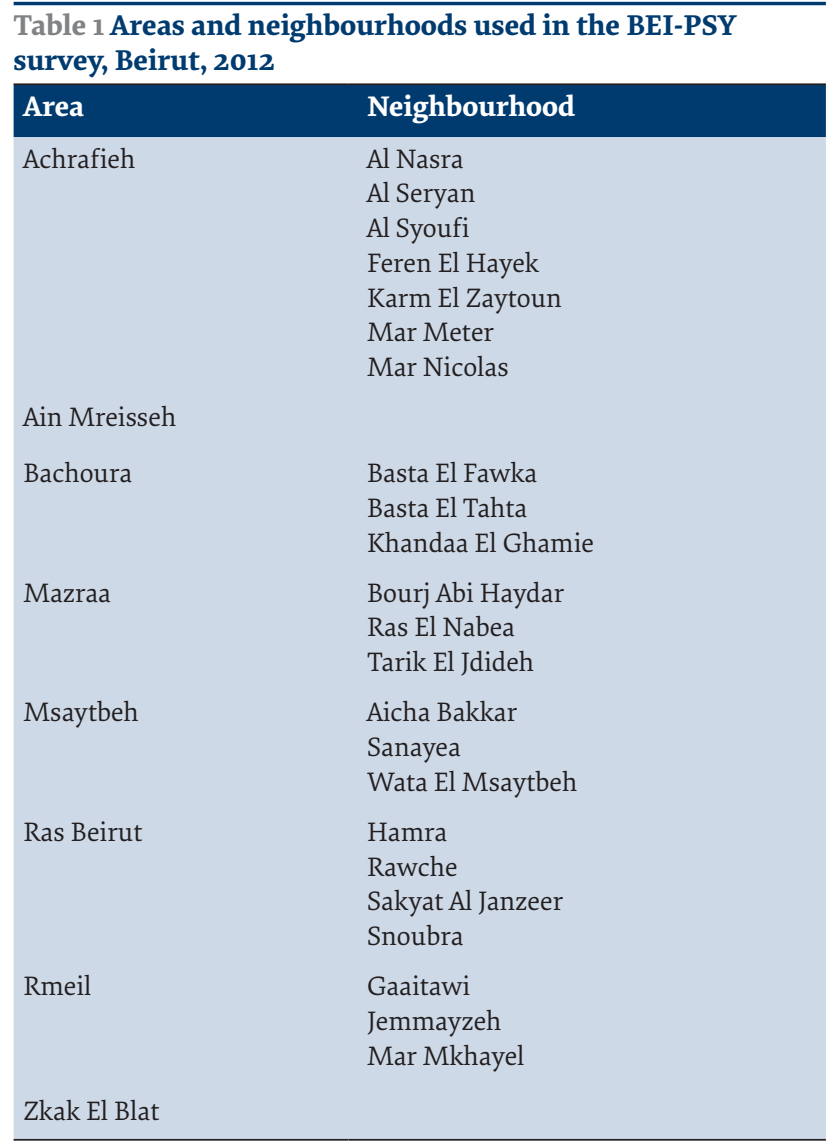

and then equally divided across the various neighbourhoods within the area. Neighbourhoods were purposively selected to include a diversity of socioeconomic levels. Full details of the survey methodology are given in the BEI-PSY (12). However, the selection of households was not entirely conducted using probability sampling for logistical reasons, and the implications are addressed in the Discussion section. The research company conducting the fieldwork had acquired all maps from the Lebanese Army through their Directorate of Geographic Affairs and GIS/Transport, a specialized geographic information system company in Lebanon.

A total of 9061 households were approached and 510 completed adolescent/parent pair questionnaires were collected. In cases where there was a specific disability, such as severe mental retardation (3 cases), the surveyors tried as much as possible to interview the selected child, focusing on the parent interview. Eligible adolescents with hearing problems were excluded. Data collectors recorded all fieldwork details and outcomes (Table 2).

Among the households approached, 3517 were identified as ineligible, including units that were nonresidential or under construction and those that did not have an adolescent in the specified age range (Figure 1). A total of 1004 households included eligible children; 510 (51\%) completed interviews, 363 (36\%) were refusals, and the remaining $13 \%$ were either breakoffs or cases where the randomly selected child was unavailable during both visits. 
Table 2 Interview template used in the BEI-PSY survey, Beirut, 2012

\begin{tabular}{|c|c|}
\hline $\begin{array}{l}\text { First attempt } \\
\text { Date \& time: } \\
\text { Outcome }\end{array}$ & $\begin{array}{l}\text { Second attempt } \\
\text { Date \& time: } \\
\text { Outcome }\end{array}$ \\
\hline $\begin{array}{l}\text { Interview } \\
\text { Complete interview } \\
\text { Partial interview - but asked to return on } \\
\text { Partial interview - but asked not to come back - circle also } 2.1\end{array}$ & $\begin{array}{l}\text { Interview } \\
\text { Complete interview } \\
\text { Partial interview - but asked to return on } \\
\text { Partial interview - but asked not to come back - circle also } 2.1\end{array}$ \\
\hline $\begin{array}{l}\text { Eligible } \mathrm{HH} \text {, but non-interview (non-response) } \\
\text { Refusals : a responsible person refused } \\
\text { at screening (before any explanation) } \\
\text { after screening (after some explanation of the study) } \\
\text { No one was at HH (non-contact) } \\
\text { R was selected but R was not at HH/could not be reached (non-contact) } \\
\text { Language barrier: selected R cannot speak/read Arabic (do not come } \\
\text { back) } \\
\text { Selected R mentally disabled: interview parent only and child as } \\
\text { possible } \\
\text { Selected R physically disabled with a temp condition }\end{array}$ & $\begin{array}{l}\text { Eligible HH, but non-interview (non-response) } \\
\text { Refusals: a responsible person refused } \\
\text { at screening (before any explanation) } \\
\text { after screening (after some explanation of the study) } \\
\text { No one was at HH (non-contact) } \\
\text { R was selected but R was not at HH/could not be reached (non-contact) } \\
\text { Language barrier: selected R cannot speak/read Arabic (do not come } \\
\text { back) } \\
\text { Selected R mentally disabled: interview parent only and child as } \\
\text { possible } \\
\text { Selected R physically disabled with a temp condition }\end{array}$ \\
\hline $\begin{array}{l}\text { Unknown } \mathrm{HH} \text { eligibility } \\
\text { Unable to access building } \\
\text { Able to access building but unable to reach anyone at HH (no one } \\
\text { answered the door) } \\
\text { Able to access HH, no one at home (maid answered the door) } \\
\text { Other reason }\end{array}$ & $\begin{array}{l}\text { Unknown } \mathrm{HH} \text { eligibility } \\
\text { Unable to access building } \\
\text { Able to access building but unable to reach anyone at } \mathrm{HH} \text { (no one } \\
\text { answered the door) } \\
\text { Able to access } \mathrm{HH} \text {, no one at home (maid answered the door) } \\
\text { Other reason }\end{array}$ \\
\hline $\begin{array}{l}\text { HH not eligible (do not come back): } \\
\text { Office } \\
\text { HH is occupied, but no child fits eligibility criterion } \\
\text { Other reason }\end{array}$ & $\begin{array}{l}\text { HH not eligible (do not come back): } \\
\text { Office } \\
\text { HH is occupied, but no child fits eligibility criteria } \\
\text { Other reason }\end{array}$ \\
\hline
\end{tabular}

See Table 2 for definitions of codes.

$\mathrm{HH}=$ household.

$R=$ respondent

Response rates (RRs) were calculated assuming a 3.5 ratio of ineligibility to eligibility, which was deduced from the pilot surveys. The formula used to make these calculations is:

$$
\mathrm{RR}=\mathrm{I} /[(\mathrm{I}+\mathrm{P})+(\mathrm{R}+\mathrm{NC}+\mathrm{O})+\mathrm{e}(\mathrm{UH})]
$$

where: $\mathrm{I}$ = completed interview, $\mathrm{P}=$ partial interviews (ones without enough data to consider), $\mathrm{R}=$ refusals, $\mathrm{NC}$ = no contact, $\mathrm{O}=$ other, $\mathrm{UH}=$ unknown households, and $\mathrm{e}=$ estimated proportion of unknown eligible who are eligible (23). Rates varied by area ranging between $10 \%$ and $32 \%$ (Tables 3 and 4). The RR was calculated as $22 \%$, with $9 \%$ being the minimum [total completed interviews ( $\mathrm{n}=510$ ) divided by "all households except ineligible"] and $51 \%$ the maximum, assuming all households of "unknown eligibility" were ineligible.

\section{Study tools}

Participants completed a structured interview and a series of Arabic rating scales. The randomly selected child completed the self-report version of the Strengths and difficulties questionnaire (SDQ) (24), and the Peer relations questionnaire (PRQ) (25). The PRQ measures 3 constructs: bullying, being victimized, and pro-social behaviour (26) .We used the Arabic version of the SDQ which has been validated among a sample of Yemeni children (26); the original English PRQ (25) was translated to Ara- bic by the team and back-translated. The SDQ is a measure of social, emotional and behavioural functioning (24). The selected parents completed the demographic sheet (including questions related to history of treatment seeking), the Attitudes towards psychiatric illness (ATPI) questionnaire (27), and the parent version of the SDQ. The ATPI is composed of 4 items assessing stigma associated with mental illness (27).

The parent and child were also administered the Development and well-being assessment (DAWBA) (28), a structured interview used to formulate a psychiatric diagnosis of a child/adolescent based on the Diagnostic and statistical manual of mental disorders (DSM-IV-TR) and the International classification of diseases (ICD-10) criteria $(28,29)$. Clinical raters integrated information from the structured questions, the DAWBA-generated diagnoses, and from subjective transcripts, to come up with a clinical diagnosis that either accepts or overturns the computer diagnosis. Each DAWBA interview was rated individually by either a child and adolescent psychiatrist (FM) or a psychologist (PZ); the 2 raters had confirmed inter-rater reliability (29). The Arabic version of the interviewer-based paper and pencil DAWBA was used, which has good inter-rater reliability with coefficients of 0.93 for disruptive disorders, 0.82 for mood disorders, 0.72 for anxiety disorders and 0.68 for other disorders (29). 


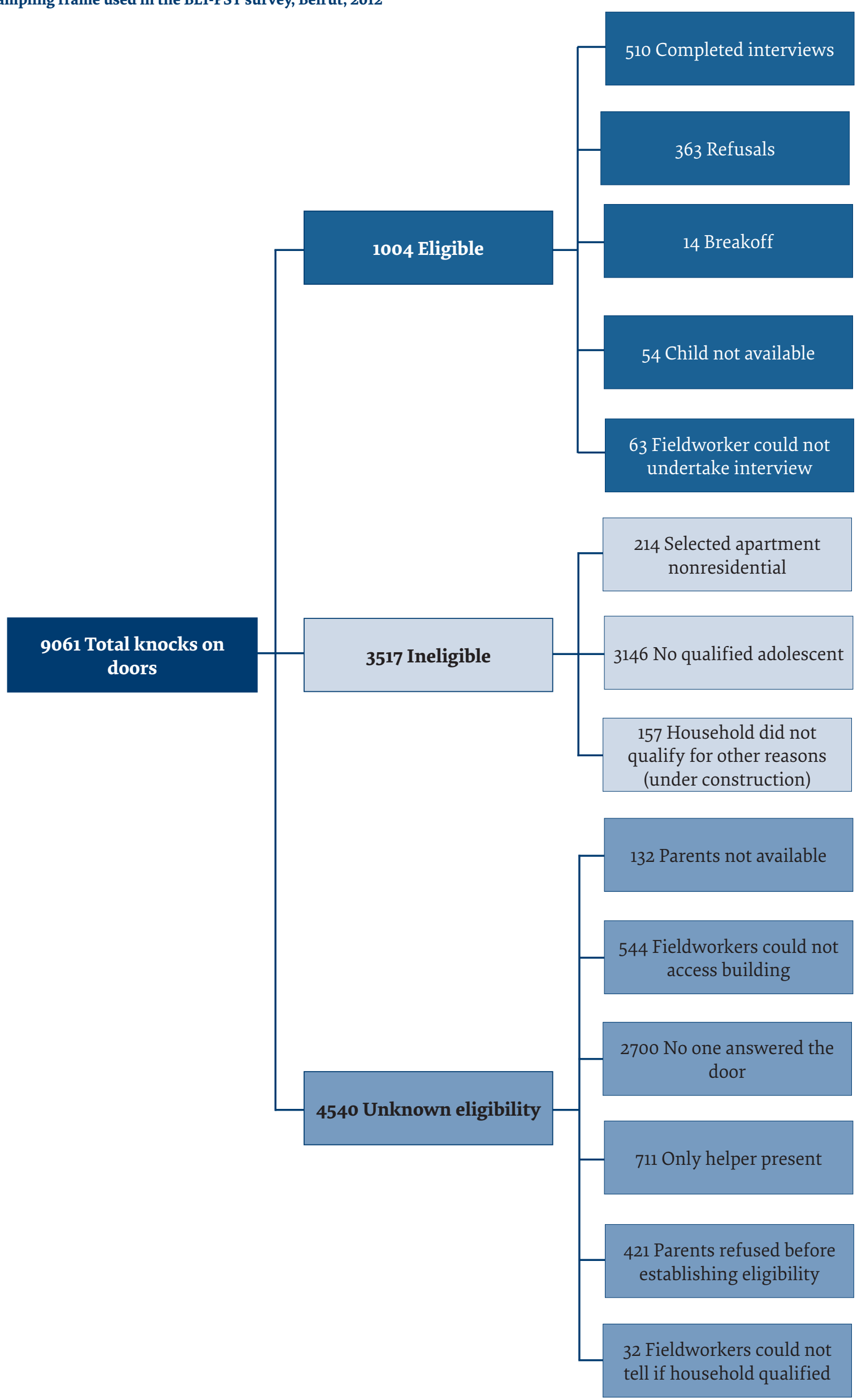




\begin{tabular}{|c|c|c|c|}
\hline Description & Code $^{a}$ & No. of households & Eligibility \\
\hline Field workers could not access the building & 3.1 & 9 & Unknown eligibility \\
\hline No one opened the door & 3.2 & 86 & Unknown eligibility \\
\hline Only the helper was present in the house & 3.3 & 6 & Unknown eligibility \\
\hline $\begin{array}{l}\text { Field workers could not tell whether the households was an applicable } \\
\text { case as the parents refused before hearing any explanation about the } \\
\text { study }\end{array}$ & 3.4 & 9 & Unknown eligibility \\
\hline $\begin{array}{l}\text { Filed workers could not tell whether the household was qualified: The } \\
\text { household residents only come in the summer }\end{array}$ & 3.5 & 1 & Unknown eligibility \\
\hline The selected apartment was an office (non-residential unit) & 4.1 & 15 & Not eligible \\
\hline $\begin{array}{l}\text { The house was inhabited, but there was no qualified adolescent in the } \\
\text { specified age range }\end{array}$ & 4.2 & 139 & Not eligible \\
\hline The households did not qualify: households still under construction & 4.3 & 6 & Not eligible \\
\hline Partial interview and asked to come back later to complete it & 1.2 & 1 & Incomplete \\
\hline Partial interview and asked not to come back later & 1.3 & 1 & Refusal \\
\hline The selected child was not available at the time of the interview & 2.2 & 4 & Non-response \\
\hline The parents were not available at home at the time of the interview & 2.3 & 10 & Non-response \\
\hline $\begin{array}{l}\text { The parents refused before hearing any explanation about the study } \\
\text { although the household was an applicable case }\end{array}$ & 2.1.1 & 11 & Refusal \\
\hline $\begin{array}{l}\text { The parents refused after hearing some explanation about the study } \\
\text { although the household was an applicable case }\end{array}$ & 2.1.2 & 11 & Refusal \\
\hline The child refused to participate & 2.1.3 & 1 & Refusal \\
\hline
\end{tabular}

${ }^{a}$ Definition of codes in Figure 1

\section{Data collectors: training and quality control}

After successfully completing the required Collaborative Institutional Training Initiative course (30), data collectors were trained for a full day by a child and adolescent psychiatrist (FM), a clinical and counselling psychologist (PZ), and an epidemiologist (LG). Initially, 2 separate full training sessions were held for about 30 fieldworkers to train them on general interviewing techniques and specific survey procedures, followed by an interview simulation. A total of 22 data collectors, 12 females and 10 males, were finally involved in the fieldwork, 19 of whom (86\%) were undergraduate university students.

Following the training, the pilot phase was conducted, during which the data collectors were closely supervised and evaluated by one of the research team (LT). The pilot phase was carried out in 3 waves to accommodate all newly recruited and trained data collectors, given the large turnover. The first 2 waves of piloting were mainly used to assess the feasibility of the sampling process, residual problems in administering the scales and/or interviewing, performance of data collectors, and other logistics. The results of the third wave of piloting were used to calculate potential response rates for our survey. Debriefing sessions took place with all data collectors, both individually and collectively.

During the pilot study, data collectors were also quantitatively evaluated by members of our team using a structured form consisting of 2 parts: the first included items on a 5-point Likert scale assessing the different aspects of the interaction with the selected participant, including body language, politeness, sticking to the scripts and questions, noting down answers verbatim, and preparedness. The second part of the evaluation consisted of an open-ended section evaluating the different phases of recruitment, including the introduction and random selection procedure and the administration of each questionnaire. The interviewers were shadowed and observed by the research team for two household visits and an evaluation form was filled out based on this observation. Based on these supervisions and evaluations, some data collectors were released. Booster information sessions were held to exchange experiences and input among the retained data collectors and other members of the research team; a closed Facebook group was also created to allow for regular group discussions and feedback, particularly during data collection.

Quality control was implemented independently by the research company and by our team. A random sample of participants with completed interviews was called back by the research company and asked specific questions to validate the answers against their original survey response. Specific questions inquired whether anyone in the household was interviewed, and cross checked details of the participating child (e.g. age, whether s/he went to school, current class, if child were receiving treatment for a medical psychological or nervous case), the time spent conducting the interview, and whether the interview was completed or not. General feedback was also solicited (i.e. whether the participants had any comments on the interview and/or interviewer). Quality reports were regularly generated by the research company and shared with our team. The research team also randomly selected $10 \%$ of the sample to call-back for quality control.

During the entire fieldwork, progress reports were 


\begin{tabular}{|c|c|c|c|}
\hline Area & $\begin{array}{l}\text { Minimum } \\
\text { RR (\%) }\end{array}$ & $\begin{array}{l}\text { Maximum } \\
\text { RR (\%) }\end{array}$ & $\begin{array}{c}\text { Probable } \\
\text { RR (\%) }\end{array}$ \\
\hline Ashrafieh & 9 & 66 & 22 \\
\hline Ain Mreisseh & 4 & 71 & 11 \\
\hline Bashoura & 13 & 49 & 28 \\
\hline Mazraa & 13 & 58 & 32 \\
\hline Msaytbeh & 11 & 50 & 26 \\
\hline Ras Beirut & 6 & 54 & 14 \\
\hline Rmeil & 6 & 44 & 16 \\
\hline Zkak El Blat & 8 & 16 & 10 \\
\hline
\end{tabular}

sent periodically by the research company detailing the total number of households completed until the report date, and the outcomes of the contacts made (e.g. number of refusals, number of households that could not be accessed, number of completed interviews, etc.).

\section{Ethical considerations}

The survey was granted ethical approval by the Institutional Review Board of the American University of Beirut. Informed consent and assents were obtained from participating parents and children/adolescents. All procedures performed in studies involving human participants were in accordance with the ethical standards of the institutional and/or national research committee and with the 1964 Helsinki declaration and its later amendments or comparable ethical standards.

Fieldworkers were provided with an emergency number to contact in case they encountered an adolescent who responded positively to one of the self-harm or suicidal ideation questions. The clinician who received these calls spoke with the adolescent, assessed the level of risk of self-harm and, if necessary, spoke with the parent and recommended referral accordingly. In addition, all participating parents were provided with a referral list of nongovernmental organizations that offer psychological services, and hospitals that have psychiatric departments in Beirut. Parents and adolescents were also given the option of meeting with the investigators 2 or 3 months following data collection in order to be briefed about the psychiatric symptoms of the adolescent.

As a token of appreciation, participants were provided with a small stationery kit. All authors certify responsibility for this manuscript.

\section{Discussion}

\section{Sampling frames and target sample}

Many international population-based surveys have used national registries and databases for their household surveys $(15,31,32)$, or have been conducted by governments or government-funded agencies or institutions $(33,34)$. In Lebanon, the last population census was conducted in 1932, and given the lack of sufficient resources to create new lists and/or maps of Beirut, we capitalized in the present study on the experience and expertise of a renowned research company in assisting with the creation of the sampling frame. Future surveys, mental health or other, should budget for complete household listing of the areas to be surveyed (e.g., using GPS or satellite imagery) to generate a more complete sampling frame and enable a robust probability sampling technique (21).

When less than ideal sampling is employed, it is crucial for validity purposes to compare sample characteristics with that of the target population. In the BEI-PSY study, the sample appears to reflect the general demographic and socioeconomic trends within Lebanon. The ratio of males to females was only slightly higher than national estimates, and parental level of education was in line with Central Administration of Statistics data on maximal education levels in the Lebanese population (22), with about a third of the sample having less than secondary level education and a third of the adolescent sample having one or both of their parents complete a college education. The average monthly income per producer in Beirut in 2007 was US\$ 606 (22); our sample was average in terms of socioeconomic status with the median households (yearly) income US\$100o or less; only $12 \%$ reported a household income of more than \$US 2000. However, comparing the sample to national distribution of residents by sex, education and income does not guarantee lack of bias, or address fully the representativeness of the sample.

\section{Household access and response rates}

Access to households was a major source of constraint in the survey. Noteworthy are the number of households that remained of unknown eligibility after 2 contact attempts; 4540 households were labelled as such, e.g. because no one answered or opened the door $(\mathrm{n}=2700$; $59 \%)$, parents were not available $(\mathrm{n}=132 ; 3 \%)$, fieldworkers could not access the building $(\mathrm{n}=544 ; 12 \%)$, etc. (Figure 1 ). One possibility is that there was really no one home, but another quite probable reason could be the country's uncertain security level, rendering residents both cautious and reluctant to open their doors to strangers. Quite challenging were also the gated buildings and areas restricted for security or political reasons (it is not uncommon in Lebanon for politicians to have a restricted-access radius around their residences).

Inability to determine eligibility after 2 visits has repercussions on survey results, both in terms of low response rate and selection bias. Eligibility remained undetermined in almost half of the households approached, particularly in areas perceived to be of a higher socioeconomic status. This is similar to a study in Brazil where researchers also found it hard to recruit respondents from more affluent areas, possibly because they were suspicious of surveyors and afraid of being robbed (31). In such circumstances, and when noncontact is high, techniques to improve outcomes could entail increasing the number of households contacts (which in our case were limited to two due to budget constraints) 
(35). In the NEMESIS study, for instance, a minimum of 10 calls or visits were made to establish contact with participants and achieve a response rate of $64 \%$ (36). Similarly in the National Comorbidity Survey Replication, unlimited in-person contact was attempted, reaching a $71 \%$ response rate for primary respondents and $80 \%$ when taking into account secondary predesignated respondents (16). Other strategies for optimizing contact rates include mixing and adjusting interviewing hours (between weekdays/weekends, daytime/evening) (21,35), increasing the length of the data collection period if possible, and/or seeking supplemental information about households of unknown eligibility (information about at-home patterns from neighbours, doormen or building managers) (21,35).

The response rate in this study $(22 \%)$ is considerably lower than that reported for another household survey conducted in 2002-2003 among adults in Beirut (60\%) (3), but low response rates are certainly not unique to this study or to Lebanon, with declining response rates becoming a major global concern for all data collection modes, including household interviews (37). Reasons for this global phenomenon could be the rise in the number of requests to participate in research (some of which are marketing rather than scientific surveys), or the general time and energy demands of participating in surveys. The low response rate in this particular study could additionally be attributed to the growing, but not yet established, research-oriented culture in Lebanon (29). Efforts to educate the local community about the value of participating in research are limited to academic centres and universities and little is being done on the national level to educate the general public. In the Irish Longitudinal Study on Ageing, several strategies were employed to improve response rates including a series of advertisements on local radio, appearing on television interviews and sending information brochures about the study to local religious, community and nongovernmental institutions (11). Enhancing cooperation rates in surveys could thus begin pre-contact, by publicizing the survey through press releases and media (11,38). Other mechanisms could include sending advance letters, for example to alert household members of an upcoming visit by interviewers (35); the detailed sealed letter could be mailed or delivered to the doormen or building manager to be distributed to the selected floors and apartments.

During data collection, recruiting interviewers who are known to or trusted by the community members, or using a neutral agency or media outlet to support the survey and encourage participation, could also help reduce refusals (21). Governmental support, whether financial and/or pragmatic assistance in the field by publicly endorsing the study and encouraging people to participate in it, could be useful only in contexts where governments are perceived favourably; otherwise, members of the community may become even more reluctant to participate in government funded or supported research initiatives (20).

Successful collaborations between public and private institutions, such as ministries of health, hospitals and universities could also improve response rates. For example, the New Zealand Mental Health Survey was conducted following consultation and support from the Ministry of Health as well as groups of experts from the mental health field (39). In countries where armed conflict or political instability may prevail, establishing good relationships with key community members (gate keepers) can prove especially useful for enhancing access to communities and subsequently households (21,38). Other suggested techniques to overcome field challenges include offering higher monetary incentives at the second contact $(36,40)$.

If initial contacts do result in a refusal, refusal conversion methods could be attempted by mailing a letter for example to reiterate the importance of their participation to the overall success of the study (35). As a worst case scenario, attempts should be made to seek a very short interview that collects the basic data necessary for post survey adjustments (35).

\section{Funding constraints and their implications}

Given no prior estimates for child mental health disorders in the general population of Lebanon, a prevalence of $50 \%$ was assumed when calculating sample size, which yields the largest possible sample size $(n=384)$. Given the clustered sampling technique, a design effect (deff $=2$ ) was considered (i.e. $n=768$ ); in the absence of an available design effect, the rule of thumb has been to use either 1.5 or 2 (41). Originally, we had aimed at interviewing 1000 participants from Greater Beirut, including its southern and northern suburbs; however, due to budget constraints, the target sample size was reduced to 500, and the study was restricted to administrative Beirut. Pilot survey results (number of non-responders, refusals, and non-eligible) were used to estimate the number of households needed to be approached to achieve 500 completed interviews, and about 11000 households were estimated to be needed (9061 were actually approached).

Evidently, budget constraints have several repercussions on the design and implementation of household surveys including but not limited to working with a non-optimal sampling frame, reducing desired sample size, restricting target areas, and/or inability to enhance contact rates. Tight research budgets have indeed been identified as one of the challenges of conducting research in the Middle East and Africa regions, and potential future solutions may include establishing a specific budget for research at governmental level (20).

One decision taken by the investigators to cut down on the study expenses and implement the study with the available budget was to volunteer their time. The research team also engaged in several negotiations with the research company to help them see the value of undertaking this work meticulously at a relatively low cost.

\section{Tool selection and validation}

Using Arabic language instruments in this study required 
significant preparation that spanned approximately 2 years. First, instruments in Arabic were difficult to obtain because many are published in journals not readily available in online databases. Second, tools translated into Arabic and tested in a given society are not readily transferable to another Arabic-speaking country, the Arabic language varies by geography to the extent that vernacular Arabic is not mutually comprehensible across countries. Arabic also varies by purpose: a formal variety of Arabic, referred to as Modern Standard Arabic (MSA), is used in literature, education and formal media outlets while vernacular Arabic is used in everyday life, and differs across countries. Therefore, a tool developed using Yemeni Arabic may not be readily understood in Lebanon and vice-versa. Although MSA is thought to be mutually familiar in all Arabic speaking countries, instruments written in MSA risk being too formal and even prohibitive to people with low educational attainment. Tools written strictly in MSA have been described as being "distant" from everyday experiences and not "user-friendly" in accessing psychological constructs (42). In view of these language challenges, existing Arabic instruments such as the DAWBA had to be customized to the Lebanese dialect, while new instruments such as the PRQ had to be developed using a balanced approach to MSA that is clear and familiar to native speakers in Lebanon. Adaptation was also necessary at the level of administration method. During piloting, the DAWBA section on substance-use was judged to be intrusive, and unlikely to yield honest responses in an interview format. Therefore, this section was reformatted to be self-administered in order to enhance the validity of responses.

When necessary, tools were translated from English to Arabic, back-translated, and reviewed by content experts with sequential changes in wording until the Arabic version was successfully piloted. It is worth noting that there is new and growing evidence that recommends a "team translation approach" for survey instrument production, in contrast to back translation. Briefly, the approach entails that a group of people work together to produce, independently from each other, initial translations, which are thereafter assessed by reviewers along with the translators, and finally regarded by one (or more) adjudicator as being ready for pretesting and finalized for fieldwork (43). This approach is particularly useful when the purpose of the study is comparative (cross-cultural) with a primary aim of comparing data across countries and cultures.

The choice of the diagnostic interview is definitely worth discussion. The DAWBA was chosen due to its unique features that make it particularly useful, including the solicitation of open-ended responses following closeended questions, which can help detect and resolve possible inconsistencies vis-à-vis the close-ended questions (due to language, culture, etc.). Nonetheless, the DAWBA is a long structured interview with many skip rules; the interviewer-administered paper-and-pencil version used in this survey (versus the online version) is particularly time-consuming and liable for more random human errors at the level of the interview and/or data entry. The decision not to use the computerized version was made considering a few factors such as the cost of purchasing the equipment, or the reduced fluency of typing in Arabic.

\section{Conclusion}

This was the first attempt to survey children and adolescents in the general population of Lebanon, using a structured interview, rating scales and open-ended questions that allow for the establishment of baseline prevalence estimates for various mental health disorders, and the identification of correlates among non-institutionalized community sample of adolescents (10). Despite the many methodological challenges faced, the study was completed and its findings have significantly contributed to the local, as well as global prevalence data for mental disorders among youth (44).

The study also sets the example that a sound epidemiological survey is possible even where resources are limited and contexts challenging, either due to security issues or absence of a research culture. Documentation and dissemination of the main challenges faced and the lessons learned is greatly needed and crucial for ensuring that future surveys, particularly within the same or similar contexts, are conducted with the fewest possible methodological issues.

\section{Acknowledgement}

We would like to thank Dr Robert Goodman for his guidance and support during this study.

Funding: This study was funded by the Medical Practice Plan at the American University of Beirut.

Competing interests: None declared.

\section{Problèmes et solutions contextuels à la réalisation d'une enquête sur la santé mentale des adolescents dans les ménages vivant dans un pays en développement}

\section{Résumé}

Les données épidémiologiques obtenues auprès des adultes libanais et les efforts accrus de planification des politiques et des services ont démontré l'importance de l'étude des troubles psychiatriques au sein de la population adolescente. En réponse à ce besoin, l'enquête épidémiologique de Beyrouth sur l'état psychologique des jeunes a été menée auprès d'un 
échantillon communautaire pour estimer la prévalence des troubles psychiatriques et leurs corrélats chez les adolescents. L'objectif principal de ce rapport est de fournir une synthèse du processus de recherche et des problèmes rencontrés lors de la réalisation de la première enquête sur la santé mentale de la population adolescente au Liban. Le présent rapport examine les difficultés rencontrées et les enseignements tirés suite à la réalisation d'une telle enquête. Parmi les thèmes abordés, l'on peut mentionner l'absence d'un cadre d'échantillonnage adéquat, la réalisation d'une étude solide avec un financement limité et l'absence d'une culture de recherche. Le présent rapport présente des recommandations fondées sur des données probantes à des fins d'enquêtes futures similaires. Le rapport établit également qu'une enquête épidémiologique solide est possible, même lorsque les ressources sont limitées et dans le cadre de contextes difficiles tels que des problèmes de sécurité ou l'absence d'une culture de recherche.

$$
\begin{aligned}
& \text { التحدِّيات والحلول السياقية لإجر اء مسح صحي نفسي للمر اهقين في أحد البلدان النامية }
\end{aligned}
$$

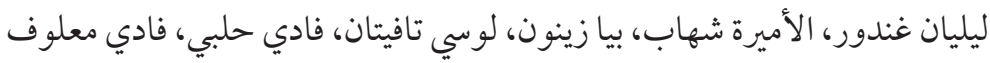

$$
\begin{aligned}
& \text { الخلاصة لياصة }
\end{aligned}
$$

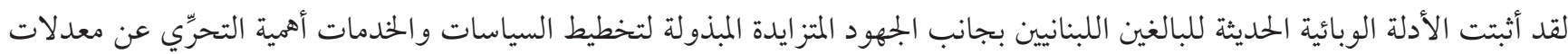

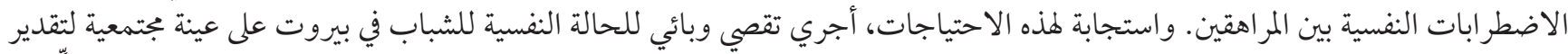

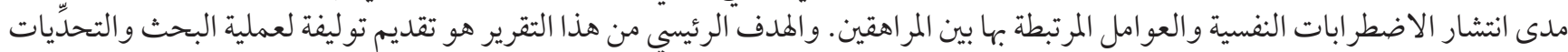

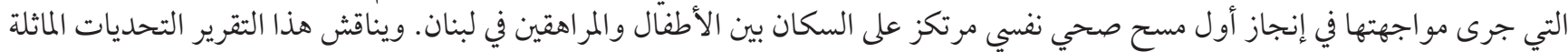

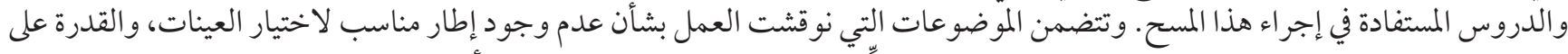

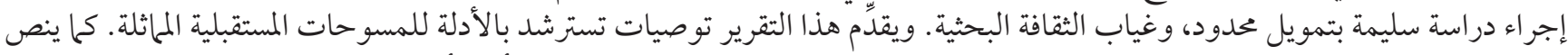

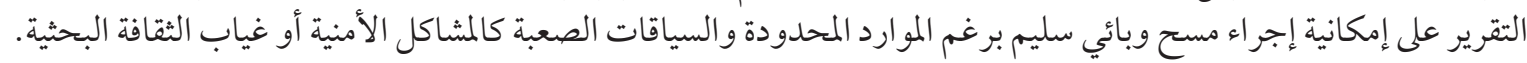

\section{References}

1. Mental health and substance use- prevention, promotion, and treatment. Situation analysis and strategy for Lebanon $2015-2020$. Beirut: Ministry of Public Health; 2015. (http://www.mhinnovation.net/sites/default/files/downloads/resource/MH\%20strategy\%20LEBANON\%20ENG.pdf, accessed 14 March 2018).

2. Karam EG, Salamoun MM, Mneimneh ZN, Fayyad JA, Karam AN, Hajjar R, et al. War and first onset of suicidality: the role of mental disorders. Psychol Med. 2012 Oct;42(10):2109-18. https://doi.org/10.1017/So033291712000268 PMID:22370047

3. Karam EG, Mneimneh ZN, Karam AN, Fayyad JA, Nasser SC, Chatterji S, et al. Prevalence and treatment of mental disorders in Lebanon: a national epidemiological survey. Lancet. 2006 Mar 25;367(9515):1000-6. https://doi.org/10.1016/So140-6736(06)68427-4 PMID:16564362

4. Farhood LF, Dimassi H. Prevalence and predictors for post-traumatic stress disorder, depression and general health in a population from six villages in South Lebanon. Soc Psychiatry Psychiatr Epidemiol. 2012 Apr;47(4):639-49. https://doi.org/10.1007/ s00127-011-0368-6 PMID:21455787

5. Husain F, Anderson M, Lopes Cardozo B, Becknell K, Blanton C, Araki D, et al. Prevalence of war-related mental health conditions and association with displacement status in postwar Jaffna District, Sri Lanka. JAMA. 2011 Aug 3;306(5):522-31. https://doi. org/10.1001/jama.2011.1052 PMID:21813430

6. Aoun A, Garcia FD, Mounzer C, Hlais S, Grigioni S, Honein K, et al. War stress may be another risk factor for eating disorders in civilians: a study in Lebanese university students. Gen Hosp Psychiatry. 2013 Jul-Aug;35(4):393-7. https://doi.org/10.1016/j. genhosppsych.2013.02.007 PMID:23557894

7. Mahfoud ZR, Afifi RA, Haddad PH, Dejong J. Prevalence and determinants of suicide ideation among Lebanese adolescents: results of the GSHS Lebanon 2005. J Adolesc. 2011 Apr;34(2):379-84. https://doi.org/10.1016/j.adolescence.2010.03.009 PMID:20434762

8. Richa S, Rohayem J, Chammai R, Kazour F, Haddad R, Hleis S, et al. ADHD prevalence in Lebanese school-age population. J Atten Disord. 2014 Apr;18(3):242-6. https://doi.org/10.1177/1087054712445065 PMID:22628148

9. Karam EG, Mneimneh ZN, Dimassi H, Fayyad JA, Karam AN, Nasser SC, et al. Lifetime prevalence of mental disorders in Lebanon: first onset, treatment, and exposure to war. PLoS Med. 2008 Apr 1;5(4):e61. https://doi.org/10.1371/journal.pmed.0050061 PMID:18384228

10. Maalouf FT, Ghandour LA, Halabi F, Zeinoun P, Shehab AA, Tavitian L. Psychiatric disorders among adolescents from Lebanon: prevalence, correlates, and treatment gap. Soc Psychiatry Psychiatr Epidemiol. 2016 08;51(8):1105-16. https://doi.org/10.1007/ s00127-016-1241-4 PMID:27246607

11. Whelan BJ, Savva GM. Design and methodology of the Irish Longitudinal Study on Ageing. J Am Geriatr Soc. 2013 May;61 Suppl 2:S265-8. https://doi.org/10.1111/jgs.12199 PMID:23662718 
12. Eapen V, Jakka ME, Abou-Saleh MT. Children with psychiatric disorders: The Al Ain community psychiatric survey. Can J Psychiatry. 2003 Jul;48(6):402-7. https://doi.org/10.1177/070674370304800607 PMID:12894615.

13. Eapen V, Swadi H, Sabri S, Abou Saleir M. Childhood behavioural disturbance in a community sample in Al-Ain, United Arab Emirates. East Mediterr Health J. 2001 May;7(3):428-34. PMID:12690763

14. Mullick MSI, Goodman R. The prevalence of psychiatric disorders among 5-10 year olds in rural, urban and slum areas in Bangladesh: an exploratory study. Soc Psychiatry Psychiatr Epidemiol. 2005 Aug;40(8):663-71. https://doi.org/10.1007/s00127-005-09395 PMID:16091858

15. Viana MC, Teixeira MG, Beraldi F, Bassani IdS, Andrade LH. Sao Paulo Megacity Mental Health Survey - a population-based epidemiological study of psychiatric morbidity in the Sao Paulo metropolitan area: aims, design and field implementation. Rev Bras Psiquiatr. 2009 Dec;31(4):375-86. PMID:20098829

16. Kessler RC, Berglund P, Chiu WT, Demler O, Heeringa S, Hiripi E, et al. The US National Comorbidity Survey Replication (NCS-R): design and field procedures. Int J Methods Psychiatr Res. 2004;13(2):69-92. https://doi.org/10.1002/mpr.167 PMID:15297905

17. Slade T, Johnston A, Oakley Browne MA, Andrews G, Whiteford H. 2007 National Survey of Mental Health and Wellbeing: methods and key findings. Aust N Z J Psychiatry. 2009 Jul;43(7):594-605. https://doi.org/10.1080/00048670902970882 PMID:19530016

18. Syed EU, Hussein SA, Mahmud S. Screening for emotional and behavioural problems amongst 5-11-year-old school children in Karachi, Pakistan. Soc Psychiatry Psychiatr Epidemiol. 2007 May;42(5):421-7. https://doi.org/10.1007/s00127-007-0188-x PMID:17450455

19. Jaalouk D, Okasha A, Salamoun MM, Karam EG. Mental health research in the Arab world. Soc Psychiatry Psychiatr Epidemiol. 2012 Nov;47(11):1727-31. https://doi.org/10.1007/s00127-012-0487-8 PMID:22388974

20. Lages CR, Pfajfar G, Shoham A. Challenges in conducting and publishing research on the Middle East and Africa in leading journals. Int Mark Rev. 2015;32(1):52-77. https://doi.org/10.1108/IMR-12-2014-0374

21. Mneimneh Z, Axinn WG, Ghimire D, Cibelli KL, Alkaisy MS. Conducting surveys in areas of armed conflict. In: Tourangeau R, Edwards B, Johnson TP, Wolter KM., Bates N. eds. Hard-to-survey populations. Cambridge: Cambridge University Press; 2014:134-56.

22. Central Administration of Statistics. The national survey of household living conditions. Beirut: Presidency of the Council of Ministers; 2007.

23. AAPOR TAAfPOR. Standard definitions - final dispositions of case codes and outcome rates for surveys. Oakbrook Terrace, Illinois: American Association for Public Opinion Research; 2011 (https://www.esomar.org/uploads/public/knowledge-and-standards/codes-and-guidelines/ESOMAR_Standard-Definitions-Final-Dispositions-of-Case-Codes-and-Outcome-Rates-for-Surveys. pdf, accessed 17 March 2018).

24. Goodman R. The Strengths and Difficulties Questionnaire: a research note. J Child Psychol Psychiatry. 1997 Jul;38(5):581-6. https://doi.org/10.1111/j.1469-7610.1997.tbo1545.x PMID:9255702

25. Rigby K, Slee PT. Dimensions of interpersonal relation among Australian children and implications for psychological well-being. J Soc Psychol. 1993 Feb;133(1):33-42. https://doi.org/10.1080/00224545.1993.9712116 PMID:8464217

26. Alyahri A, Goodman R. Validation of the Arabic strengths and difficulties questionnaire and the development and well-being assessment. East Mediterr Health J. 2006;12(Suppl. 2):S138-46. PMID:17361685

27. Mojtabai R. Mental illness stigma and willingness to seek mental health care in the European Union. Soc Psychiatry Psychiatr Epidemiol. 2010 Jul;45(7):705-12. https://doi.org/10.1007/s00127-009-0109-2 PMID:19680588

28. Goodman R, Ford T, Richards H, Gatward R, Meltzer H. The Development and Well-Being Assessment: description and initial validation of an integrated assessment of child and adolescent psychopathology. J Child Psychol Psychiatry. 2000 Jul;41(5):64555. https://doi.org/10.1111/j.1469-7610.2000.tb02345.x PMID:10946756

29. Zeinoun P, Bawab S, Atwi M, Hariz N, Tavitian L, Khani M, et al. Validation of an Arabic multi-informant psychiatric diagnostic interview for children and adolescents: development and Well Being Assessment-Arabic (DAWBA-Arabic). Compr Psychiatry. 2013 Oct;54(7):1034-41. https://doi.org/10.1016/j.comppsych.2013.04.012 PMID:23763871

30. CITI. Research ethics and compliance training. CITI. Miami: Collaborative Institutional Training Initiative; (https://www.citiprogram.org/, accessed 1 July 20180). .

31. Fleitlich-Bilyk B, Goodman R. Prevalence of child and adolescent psychiatric disorders in southeast Brazil. J Am Acad Child Adolesc Psychiatry. 2004 Jun;43(6):727-34. https://doi.org/10.1097/01.chi.0000120021.14101.ca PMID:15167089</jrn>

32. Ravens-Sieberer U, Kurth BM; KiGGS study group; BELLA study group. The mental health module (BELLA study) within the German Health Interview and Examination Survey of Children and Adolescents (KiGGS): study design and methods. Eur Child Adolesc Psychiatry. 2008 Dec;17(S1) Suppl 1:10-21. https://doi.org/10.1007/s00787-008-1002-3 PMID:19132300

33. AlBuhairan FS, Tamim H, Al Dubayee M, AlDhukair S, Al Shehri S, Tamimi W, et al. Time for an adolescent health surveillance system in Saudi Arabia: findings from "Jeeluna". J Adolesc Health. 2015 Sep;57(3):263-9. https://doi.org/10.1016/j.jadohealth.2015.06.009 PMID:26299553

34. Graham PL 3rd, Lin SX, Larson EL. A U.S. population-based survey of Staphylococcus aureus colonization. Ann Intern Med. 2006 Mar 7;144(5):318-25. https://doi.org/10.7326/0003-4819-144-5-200603070-00006 PMID:16520472

35. Groves RM, Couper MP. Nonresponse in household interview surveys. New York: John Wiley \& Sons; 2012. 
36. Bijl RV, van Zessen G, Ravelli A, de Rijk C, Langendoen Y. The Netherlands mental health survey and incidence study (NEMESIS): objectives and design. Soc Psychiatry Psychiatr Epidemiol. 1998 Dec;33(12):581-6. https://doi.org/10.1007/s001270050097 PMID:9857790

37. Galea S, Tracy M. Participation rates in epidemiologic studies. Ann Epidemiol. 2007 Sep;17(9):643-53. https://doi.org/10.1016/j. annepidem.2007.03.013 PMID:17553702

38. Kessler RC, Avenevoli S, Costello EJ, Green JG, Gruber MJ, Heeringa S, et al. Design and field procedures in the US National Comorbidity Survey Replication Adolescent Supplement (NCS-A). Int J Methods Psychiatr Res. 2009 Jun;18(2):69-83. https://doi. org/10.1002/mpr.279 PMID:19507169

39. Wells JE, Oakley Browne MA, Scott KM, McGee MA, Baxter J, Kokaua J; New Zealand Mental Health Survey Research Team. Te Rau Hinengaro: the New Zealand mental health survey: overview of methods and findings. Aust N Z J Psychiatry. 2006 Oct;40(10):835-44. https://doi.org/10.1111/j.1440-1614.2006.01902.x PMID:16959009

40. Monshouwer K, VAN Dorsselaer S, Verdurmen J, Bogt TT, DE Graaf R, Vollebergh W. Cannabis use and mental health in secondary school children. Findings from a Dutch survey. Br J Psychiatry. 2006 Feb;188(2):148-53. https://doi.org/10.1192/bjp.188.2.148 PMID:16449702

41. Lai MH, Kwok O. Examining the rule of thumb of not using multilevel modeling: The "design effect smaller than two" rule. J Exp Educ. 2015;83(3):423-38. https://doi.org/10.1080/00220973.2014.907229

42. Daouk-Öyry L, Zeinoun P, Choueiri L, van de Vijver, FJR. Integrating global and local perspectives in psycholexical studies: a GloCal approach. J R Personality. 2016;62:19-28. https://doi.org/10.1016/j.jrp.2016.02.008

43. Mohler P, Dorer B, Jong J, Mengyao H. Cross-Cultural Survey guidelines; team translation. translation overview. In: Guidelines for best practice in cross-cultural surveys. Ann Arbor: Survey Research Center, Institute for Social Research, University of Michigan; 2016. http://ccsg.isr.umich.edu/index.php/chapters/translation-chapter/translation-overview\#Team_translation

44. Erskine H, Baxter A, Patton G, Moffitt TE, Patel V, Whiteford HA, et al. The global coverage of prevalence data for mental disorders in children and adolescents. Epidemiol Psychiatr Sci. 2017 Aug;26(4):395-402. PMID:26786507 